\title{
Ground Hemp Fibers as Filler/Reinforcement for Thermoplastic Biocomposites
}

\author{
Amir Etaati, ${ }^{1}$ Selvan Pather, ${ }^{2}$ Moloud Rahman, ${ }^{3}$ and Hao Wang ${ }^{1}$ \\ ${ }^{1}$ Centre of Excellence in Engineered Fibre Composite, Faculty of Health, Engineering and Sciences, University of Southern Queensland, \\ Toowoomba, QLD 4350, Australia \\ ${ }^{2}$ Faculty of Science, Health, Engineering and Education, University of the Sunshine Coast, Sunshine Coast, QLD 4558, Australia \\ ${ }^{3}$ University of Southern Queensland, Toowoomba, QLD 4350, Australia
}

Correspondence should be addressed to Hao Wang; hao.wang@usq.edu.au

Received 9 January 2015; Accepted 5 May 2015

Academic Editor: Pavel Lejcek

Copyright (C) 2015 Amir Etaati et al. This is an open access article distributed under the Creative Commons Attribution License, which permits unrestricted use, distribution, and reproduction in any medium, provided the original work is properly cited.

Mechanical properties (tensile, flexural, and impact) of ground hemp fibre polypropylene composites were investigated. Ground alkali-treated hemp fibre and noil hemp fibres with various initial fibre lengths were utilized to reinforce polypropylene matrix. Firstly, the microstructural and tensile characterizations of the two types of fibres were characterized using scanning electron microscope (SEM), Fourier transform infrared analysis (FTIR), and Dynamic Mechanical Analyser (DMA). Then, the fibres were ground into different lengths of $0.2,0.5,1$, and $2 \mathrm{~mm}$; composites containing $40 \mathrm{wt} \%$ short hemp fibre and $5 \mathrm{wt} \%$ maleic anhydride grafted polypropylene (MAPP) were fabricated by means of a twin screw extruder and an injection moulding machine. Finally, influence of hemp fibre type and initial hemp fibre length on tensile property of the composites were investigated. The results revealed that addition of either noil hemp fibre or normal treated hemp fibre into the pure polypropylene matrix increased the tensile strength almost twice and stiffness of the composites more than three times. Although noil hemp fibre composite indicated slightly lower mechanical properties than the normal alkali-treated fibre composites, the difference was not significant. The analysis of the results provided the optimum initial fibre length (powder) of $0.2 \mathrm{~mm}$ hemp polypropylene composite. The results can be extended to different types of natural fibres.

\section{Introduction}

Biocomposites refer to composites that combine natural fibres, such as kenaf, jute, hemp, and sisal, with either biodegradable or nonbiodegradable polymers. Investigations on the use of natural fibres as reinforcement have introduced further applications for fibre reinforced thermoplastics in automotive and construction industries. Hemp fibre is a sustainable resource and also has shown a promising specific tensile strength to be used as reinforcement in composites for many applications [1].

Many attempts have been carried out to investigate the influence of fibre content on tensile strength and modulus of elasticity of different natural fibre reinforced polymer composites [1-3]. In general, the increase in fibre content improves tensile strengths and modulus of elasticity of the natural fibre reinforced polymer composites up to a peak value, which then decrease rapidly [1]. However, the tensile strength of the composites might be far below their potential values due to the poor interfacial adhesion between hydrophilic lignocellulosic fibres and the hydrophobic polymer matrix. A strong fibre/matrix bonding is essential for transferring the stress from the matrix to the fibres, thus taking full advantage of the natural fibres as load bearing reinforcements in the composite.

Over the past decades, many researchers have studied the effect of various compatibilizers to improve the fibre adhesion and dispersion in the composites such as maleic anhydride grafted polyolefins [4], isocyanates [5] and silanes $[5,6]$, and maleic anhydride grafted polyethylene octene elastomer (MAgPOE) $[4,7]$. Compatibilizers can modify the interface by interacting with both the fibre and the matrix, 
forming a bridge between the components and consequently enhancing the interface bonding. Among the studied compatibilizers, maleic anhydride grafted polypropylene (MAPP) is the most commonly used coupling agent to strengthen the natural fibre/matrix interfacial adhesion. Referring to the literature, the optimum tensile properties were observed after adding $3-5 \mathrm{wt} \%$ of MAPP to the natural fibre reinforced plastic composites $[1,4]$.

Injection moulding can be used to produce high quality complex parts, which is evident from the mass of plastic parts with complex shapes used in the construction, furniture, appliance, and automotive industries. Short fibres are normally used in injection moulding. Noil hemp fibre is a by-product of textile hemp fibre industries. In comparison with the hemp fibres, noil fibres are more thermally resistant because they are highly degummed and they have lower pectin content. They will be referred as noil fibre in this paper to recognise it from normal hemp fibre. They are too short to be used for fabric production but have the potential to be used as the reinforcements in injection-moulded thermoplastic composites [8].

Fibre length strongly affects mechanical properties of the composite. Surface area, which is a factor of fibre length and diameter, provides the interface to transmit the stresses from the matrix to the fibres under an applied load [9]. However, during the processing of the short fibre plastic composites, the natural fibres undergo breakage and also fibre agglomeration which reduce the reinforcing efficiency of the fibres. Our previous work revealed that hemp fibre with an average length of $1.5 \mathrm{~cm}$ is shortened to less than $200 \mu \mathrm{m}$ after fabrication of composite [10-12]. Thus, the current project attempted to use the powdered fibres, which might reduce the fibre agglomeration and might result in higher tensile properties of hemp fibre composites ultimately. Also, this paper aimed to assess whether noil hemp fibre is suitable alternative for the normal hemp fibre or not.

\section{Experimental}

2.1. Raw Materials. Noil fibres and normal hemp fibres (Figure 1) were supplied by China-Hemp Industrial Investments and Holding Co. Ltd. A M800E polypropylene (Sinopec Shanghai petrochemical Co. Ltd., China) with melt flow index of $8.0 \pm 1.5 \mathrm{~g} / 10 \mathrm{~min}$ being used as the matrix. MAPP with MA content of $1.0 \mathrm{wt} \%$ (Bondyram1001, Polyram Ram-On Industries, Israel) was used as the compatibilizer to the resin mix.

2.2. Fibre Treatments. Only normal hemp fibres were immersed in hydroxide solutions with concentration of $5 \mathrm{wt} \%$ at ambient temperature holding for 3 hours. After treatment, fibres were washed several times with $40^{\circ} \mathrm{C}$ water until its $\mathrm{PH}$ reached to 7 . Then they were oven-dried for 24 hours at $80^{\circ} \mathrm{C}$.

2.3. Fibre Characterizations Methods. Surfaces of untreated and treated normal hemp fibre and also noil fibres were examined by scanning electron microscope (JEOL 7800F SEM) operated at $5 \mathrm{kV}$. Samples were mounted onto aluminium stubs with carbon tape and then sputter coated with platinum in 120 seconds to make them conductive prior to SEM observation.

Fourier transform infrared analysis was examined using Thermo Nicolet FTIR Spectrometer model Nexus which uses a Perking-Elmer spectrometer and the standard $\mathrm{KBr}$ pellet technique. Approximately $3 \mathrm{mg}$ hemp fibres was crushed into fine particles and mixed with about $15 \mathrm{mg} \mathrm{KBr}$ and then pressed into a pellet for FTIR measurement. Effects of fibre treatment on chemical composition of hemp fibres were investigated.

A DMA Q800 V5.1 Dynamic Mechanical Analyser was used at ambient temperature to investigate the tensile properties of noil hemp fibres according to ASTM D 3822-01. Noil hemp fibres were separated and then mounted on cardboards with 7,12 , and $20 \mathrm{~mm}$ holes as gauge lengths.

Fibres were observed under a MOTIC SMZ-168 series stereo zoom microscope equipped with a CC12 Soft Imaging System to measure diameter of the fibres (average of 5 randomly measured diameters). The mounted fibres were then placed in the holders of the DMA Q800 V5.1 Dynamic Mechanical Analyser testing machine and the supporting sides of the mounting cards were cut. The fibres were then tensile tested to failure at rate of $10 \mathrm{~mm} / \mathrm{min}$.

2.4. Composite Fabrication. Then both noil fibres and treated normal hemp fibres were ground into $0.2,0.5,1$, and $2 \mathrm{~mm}$ and dried at $80^{\circ} \mathrm{C}$ for $24 \mathrm{~h}$. In order to make hemp fibre powder, hemp fibres were first chopped into snippets by a cutter mill (Pulverisette 15), and then variable-speed rotor mill (Pulverisette 14) was applied to further ground the fibrous materials into powder. The powder size was controlled by the passing times of hemp fibres through the rotor mill.

The $40 \mathrm{wt} \%$ ground fibre, $5 \mathrm{wt} \%$ MAPP, and polypropylene were compounded in a EuroLab 16XL twin-screw extruder operated at 100 revolutions per minute (rpm). The extruder barrel consisted of six heating zones, which were set at $180^{\circ} \mathrm{C}$. After cooling in air, the extruded composite material was granulated in an industrial granulator to produce composite pellets with a length around $5 \mathrm{~mm}$. The composite pellets were then dried at $80^{\circ} \mathrm{C}$ for $3 \mathrm{~h}$ before being injection moulded into tensile test specimens.

2.5. Composite Tensile Testing. The tensile strength of the specimens were evaluated using a MTS RT/10 (10 KN Capacity) according to the ASTM D638-91 standard at the specified loading rate of $10 \mathrm{~mm} / \mathrm{min}$. The composite specimens were tested to failure and the average value of 10 tensile-tested specimens was reported for each sample.

2.6. Composite Flexural Testing. Three-point flexural testing of the pure polypropylene and normal hemp fibre polypropylene composites were carried out by means of the 10 KN MTS testing machine according to the ISO 178 at a loading rate of $5 \mathrm{~mm} / \mathrm{min}$. The average of 5 specimens with cross sections of $4 \mathrm{~mm} \times 10 \mathrm{~mm}$ was reported for each sample. The span set at approximately 16 times of the thickness. 


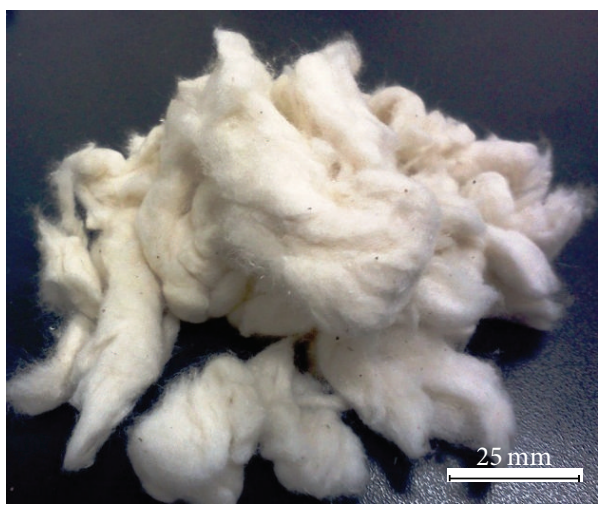

(a)

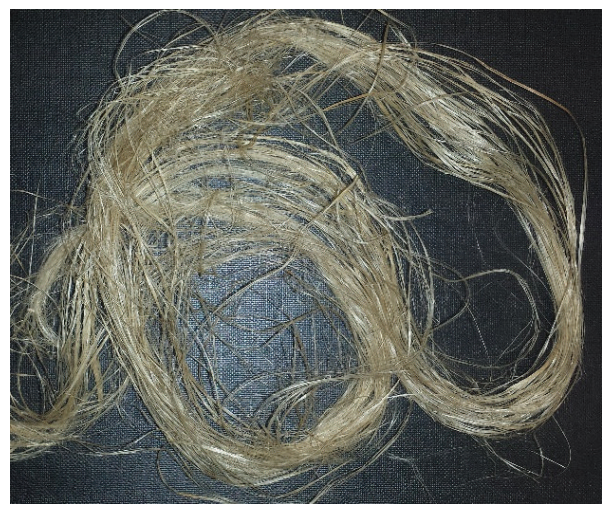

(c)

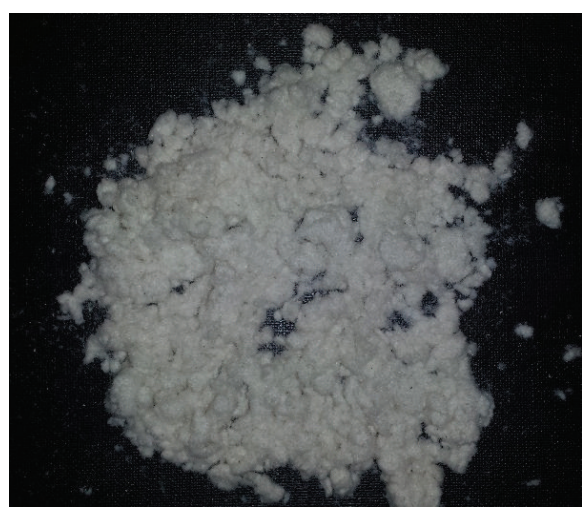

(b)

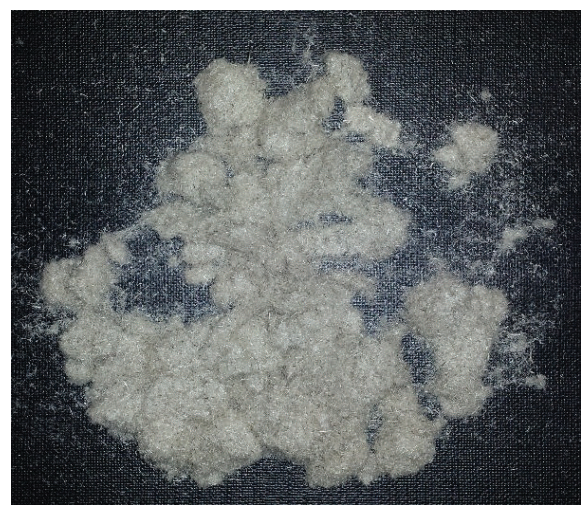

(d)

Figure 1: (a) As-received noil hemp bundles, (b) ground noil hemp fibres, (c) untreated normal hemp fibre, and (d) ground treated hemp fibres.

2.7. Composite Impact Testing. To investigate the impact performance of the composites, an unnotched Charpy impact strength test was carried out according to ASTM-D256, using an Instron Dynatup impact tester. Impact test was used to characterize the impact performance of composites with varying original fibre length. Sample dimensions were $160 \mathrm{~mm} \times 10 \mathrm{~mm} \times 4 \mathrm{~mm}$ for impact testing. A total of 5 specimens were used to determine the impact properties of the composites.

\section{Results and Discussion}

3.1. Chemical Structure of the Fibres. FTIR allows studying the influence of chemical treatment on variations of hemp fibre composition. Infrared spectrums of untreated and treated hemp and noil hemp fibres are plotted in Figure 2. Table 1 also summarizes the major peaks observed in the FTIR spectrums along with their possible sources.

As can be seen in Figure 2, one of the most noticeable changes generated by alkali treatment is the disappearance of the peak at $1732 \mathrm{~cm}^{-1}$. Referring to $[13,14]$, this can be attributed to the $\mathrm{C}=\mathrm{O}$ carbonyl stretching in carboxylic groups that mostly occur in the branched chain hemicelluloses and also in esterified and carboxylic groups in pectin. Therefore, disappearance of the mentioned peak indicates to removal of pectin and hemicellulose from surface of the fibre.

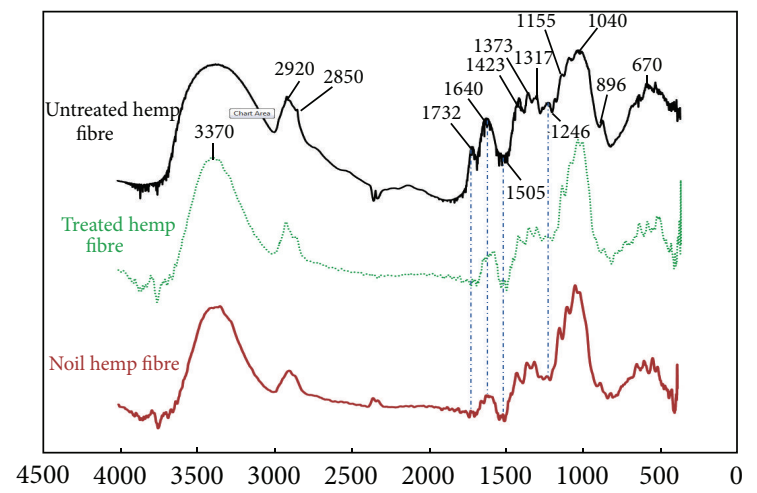

FIGURE 2: Infrared spectrums of untreated and treated hemp and noil hemp fibres.

The peak located at $1505 \mathrm{~cm}^{-1}$ which is originated from lignin can be seen in the spectrums before and after alkali treatment. Nevertheless, another peak associated to the lignin (peak at $1246 \mathrm{~cm}^{-1}$ ) was broadened after alkali treatment. It seems that alkali can remove the lignin partially from the hemp fibre's surface.

There is a blunt peak in the FTIR spectrums of the untreated fibre in the region of $3250-3550 \mathrm{~cm}^{-1}$. This peak is 
TABLE 1: The major peaks observed in the FTIR spectrums and their possible source [18-21].

\begin{tabular}{lll}
\hline Wave number $\left(\mathrm{cm}^{-1}\right)$ & Vibration & Sources \\
\hline 670 & C-OH out-of-plane bending & Cellulose \\
896 & COC, CCO, and CCH deformation and & Cellulose \\
& stretching & \\
1040 & C-C, C-OH, C-H ring, and side group & \\
1155 & vibrations & Cellulose and hemicellulose \\
1246 & C-O-C asymmetrical stretching & Cellulose and hemicellulose \\
1317 & $\mathrm{C}-\mathrm{O}$ aryl group & Lignin \\
1373 & $\mathrm{CH}$ rocking vibration & Cellulose \\
1423 & In-the-plane CH bending & Cellulose and hemicellulose \\
1505 & HCH and OCH in-plane bending vibration & Pectin, lignin, hemicelluloses, and calcium pectates \\
1640 & $\mathrm{C}=\mathrm{C}$ aromatic symmetrical stretching & Lignin \\
1732 & OH bending of absorbed water & Water \\
2850 & $\mathrm{C}=\mathrm{O}$ stretching & Xylans (hemicelluloses) \\
2920 & Esterified and carboxylic groups & Pectin \\
3370 & $\mathrm{CH}$ symmetrical stretching & Wax \\
\hline
\end{tabular}

associated to the stretching vibration of hydrogen bonding of the hydroxyl group. It is not sharp due to interfering contributions from a variety of stretching modes in the amorphous regions [14]. However, after removal of amorphous materials (hemicellulose, pectin, and lignin), the peak becomes sharp at $3370 \mathrm{~cm}^{-1}$. Besides, there is another sharp peak in the FTIR spectrum of the untreated fibres around $1640 \mathrm{~cm}^{-1}$, which is associated to the $\mathrm{OH}$ bending of absorbed water. This peak broadened after alkali treatment. Thus, treating the fibres reduced the moisture absorbance of the fibres by removal of hydrophilic lignocellulosic materials which include accessible hydroxyl groups.

It is worth mentioning that FTIR spectrum of the noil hemp fibre is so much similar to that of the treated fibre. Noil hemp fibre contains almost the same type of chemical components as the treated hemp fibres. Noil fibres can be used as reinforcement in the short fibre composites without applying further treatments to remove the lignocellulosic amorphous materials.

3.2. Fibre Morphology Analysis. The morphology of the fibres was studied by scanning electron microscope (SEM). SEM micrographs of the fibre surfaces can be seen from Figure 3 to Figure 6. Figure 3 reveals the SEM micrographs of an untreated hemp bundle whose surface is covered by the gummy polysaccharides of lignin, pectin, and hemicellulose. These materials are completely/partially removed after alkali treatment as seen in Figure 4. Removal of the lignin, pectin, and hemicellulose alters the morphology of the hemp fibre. The fibres can partially/completely be separated to elementary fibres after alkali treatment. The separation lines which show bundles of continuous elementary fibre can be viewed in Figure 4. In comparison with the untreated fibre, the treated fibres are clean but rough. The roughness enhances mechanical interlocking bonding mechanisms between fibre and the matrix, and the clean surfaces are supposed to create stronger bonding between $\mathrm{OH}$ groups of the fibre and the matrix. This observation clearly indicated that alkali treatments could remove the hemicellulose and lignin coverings from the fibre surfaces. Figure 5 shows the SEM micrographs of the noil hemp fibre and Figure 6 presents the kink band observed in noil hemp fibres.

As can be seen in Figures 5 and 6, the fibre surfaces are completely clean of gummy polysaccharides. Its cleanness implies that the noil hemp fibres are already separated to elementary fibres (microfibers) during degumming processes in textile industry. Thus, in correlation with FTIR analysis, it does not require to remove the noncellulosic materials (pectin, lignin, and hemicellulose).

Two main types of defects, which are naturally expected to be found in the cell walls of the natural fibres, are known as kink bands and microcracks. Figure 6 shows the kink band observed in SEM micrographs of noil hemp fibres. At the kink band regions, the angle of the microfibrils relative to the fibre axis differs from the angle of the surround cell wall, which corresponds to the change of crystalline orientation. It has been reported that the kink bands result in a lower strength and they are the most likely area to break during tensile tests of fibres $[15,16]$.

Figure 7 shows SEM micrographs of noil hemp fibres including microcracks in fibre cell wall along the fibre length. Microcracks lead to stress concentrations when fibres are loaded as reinforcements in composites. Not only do these defects cause variability in fibre properties but they also considerably reduce fibre strength. More defects (microcracks) are observed in noil fibres. Thus, it is expected that noil hemp fibres have a lower tensile strength than normal hemp fibres.

3.3. Strength of the Fibres. The tensile properties of single hemp fibres were evaluated for all investigating fibres. 

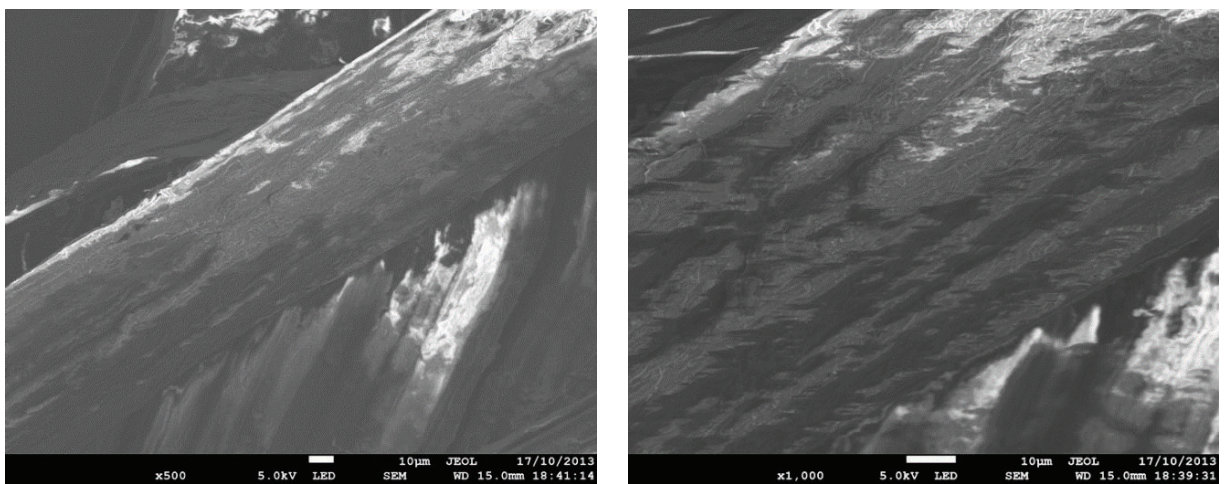

FIGURE 3: SEM micrographs of an untreated hemp bundle (the surface is covered by the gummy polysaccharides).
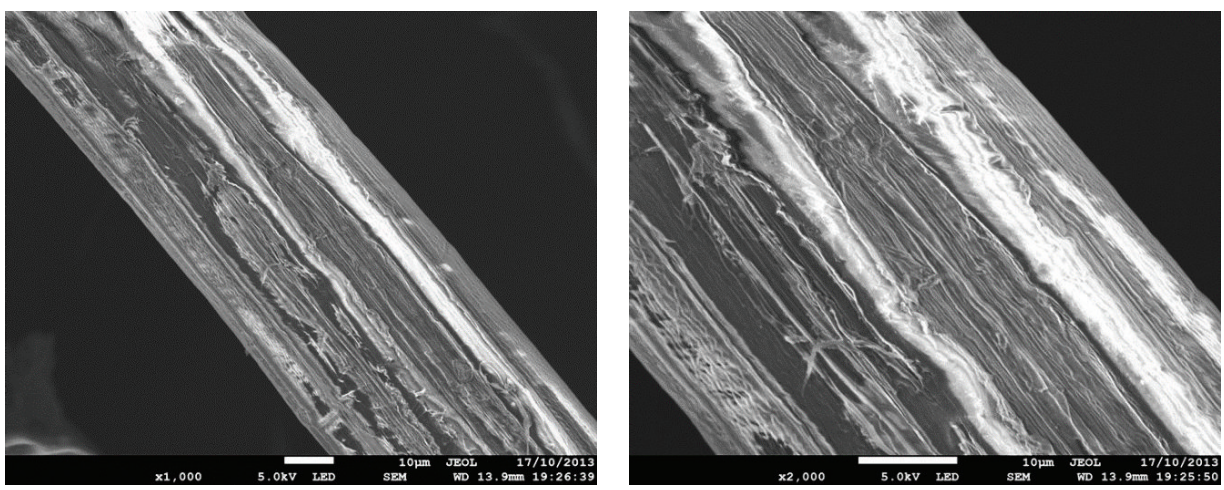

FIGURE 4: SEM micrographs of a treated hemp fibre.

Figures 8(a) and 8(b) represent the typical stress-strain curves of single noil hemp fibre and the average tensile strength values of untreated, treated, and noil hemp fibres, respectively. It can be seen that the stress versus strain curves were almost linear until fracture of the fibre. Figure $8(\mathrm{~b})$ shows that the tensile strength of the $5 \mathrm{wt} \%$ alkali treated fibre is almost $40 \%$ higher than that of the untreated fibre. The increase in tensile strength of treated fibre was due to removal of cementing materials which resulted in lower cross section of fibres in single fibre tensile testing. On the other hand, the noil hemp fibres introduced 33\% lower tensile strength compared with the alkali treated fibre. The transversal cross section of hemp is not cylindrical and there are many defects that exist along fibres length. Thus, this massive deviation is inevitable in studying characteristics of hemp fibres. Although standard deviation of the data is high, it can be concluded that tensile strength of noil hemp fibres are significantly lower than those of normal hemp fibres. It is believed that stress concentrations around microcracks can act as the sites for the initiation of fibre matrix debonding, for the formation of microcracks in the matrix or for fracture of the hemp fibre.

3.4. Tensile Properties. The tensile strengths of the pure polypropylene and their composites with $40 \mathrm{wt} \%$ fibre content with various initial fibre length are illustrated in Figure 9 and Table 2 . It can be seen that the addition of $40 \mathrm{wt} \%$ noil hemp fibre with initial length of $0.2 \mathrm{~mm}$ into the pure PP increased the tensile strength of the samples from 16.9 MPa to $32.8 \mathrm{MPa}$.

In addition, it can be noted in Figure 9 that as the initial fibre length increased, the tensile strength of the samples decreased gradually. However, the difference between composites with $0.2 \mathrm{~mm}$ and $0.5 \mathrm{~mm}$ is insignificant. It implies the fact that feeding of longer fibres in compounding and injection moulding machines cannot only improve the tensile properties of the composites but also can degrade the properties, probably due to the formation of fibre agglomerations and consequently heterogeneous dispersion of the fibres.

Young's modulus (GPa) of the samples followed the same trend (Figure 10). It increased from $1 \mathrm{GPa}$ for pure PP to 3.6 for GPa composite with $0.2 \mathrm{~mm}$ long fibres. Then it decreased gradually as the fibre length increased.

Referring to Figure 8, the average tensile strength of the noil hemp fibre was approximately $175 \mathrm{MPa}$ lower than that of the treated normal hemp fibres. However, there is no significant difference in tensile strength values between treated hemp and noil fibres composites.

3.5. Flexural Properties. Typical flexural stress-strain curves for noil hemp fibre composites are presented in Figure 11. It can be seen that the curves show initially linear portion, followed by a nonlinear region prior to the maximum flexural stress. Once the maximum stress is reached, the stress decreases just slightly until the fracture happens. 

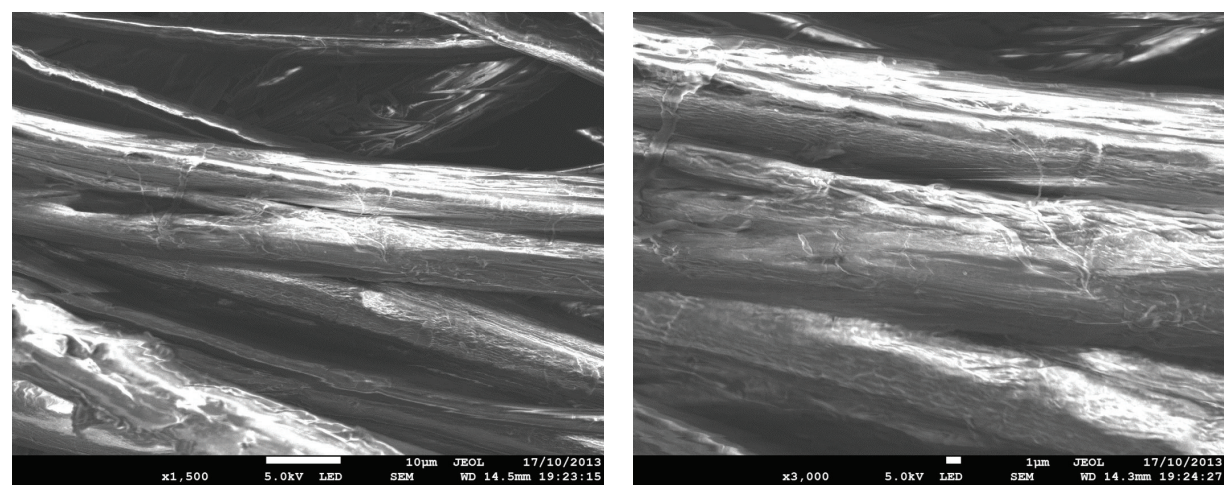

FIGURE 5: SEM micrographs of the noil hemp fibre (elementary fibres are already separated).
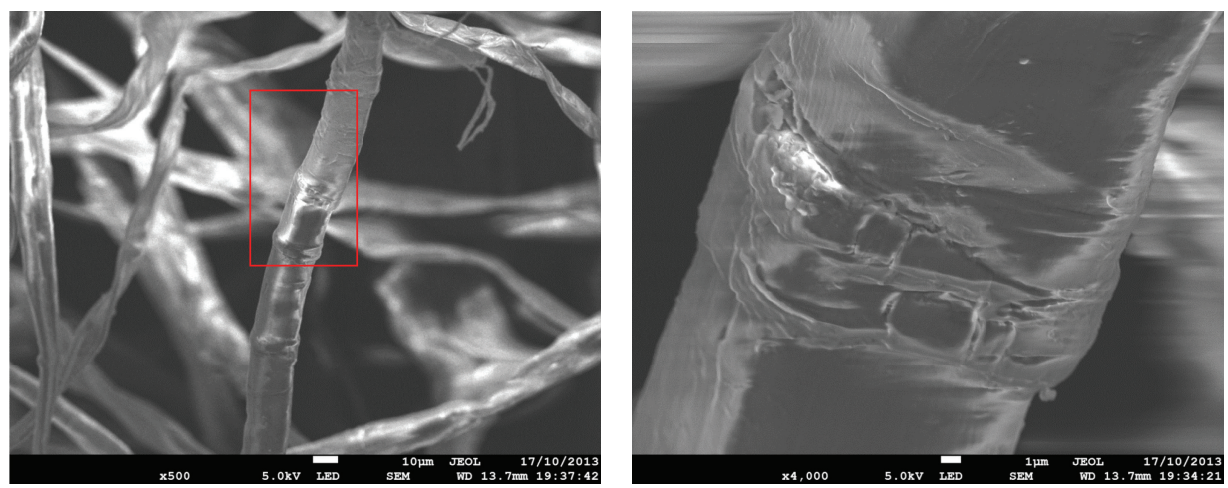

FIGURE 6: SEM micrographs of noil hemp fibres presenting the kink band clearly observed in noil hemp fibres.
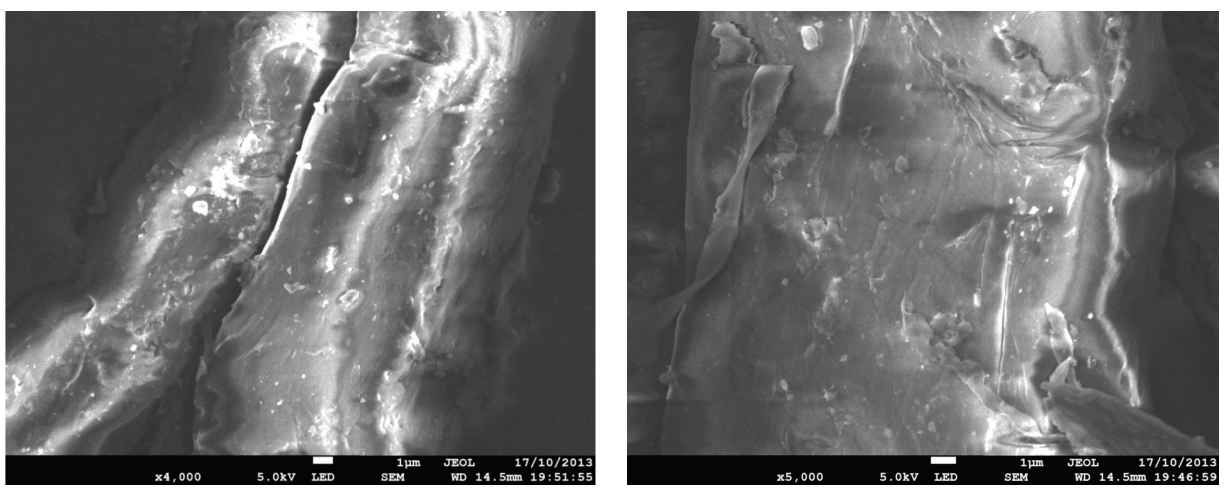

FIGURE 7: SEM micrographs of noil hemp fibres presenting the microcracks.

TABLE 2: Tensile properties of the noil hemp fibre and hemp fibre composites with varying initial fibre lengths.

\begin{tabular}{lcccc}
\hline \multirow{2}{*}{ Fibre length $(\mathrm{mm})$} & \multicolumn{2}{c}{ Noil hemp fibre } & \multicolumn{2}{c}{ Hemp fibre } \\
& Tensile strength $(\mathrm{MPa})$ & Young's modulus $(\mathrm{GPa})$ & Tensile strength (MPa) & Young's modulus (GPa) \\
\hline 0.20 & $32.85 \pm 0.67$ & $3.57 \pm 029$ & $33.61 \pm 1.35$ & $3.77 \pm 0.31$ \\
0.50 & $31.83 \pm 1.96$ & $3.29 \pm 029$ & $32.86 \pm 0.36$ & $3.38 \pm 0.67$ \\
1.00 & $27.90 \pm 2.76$ & $3.03 \pm 0.07$ & $31.53 \pm 2.23$ & $3.55 \pm 0.88$ \\
2.00 & $31.18 \pm 2.47$ & $3.32 \pm 0.30$ & $29.64 \pm 1.78$ & $3.03 \pm 052$ \\
\hline
\end{tabular}




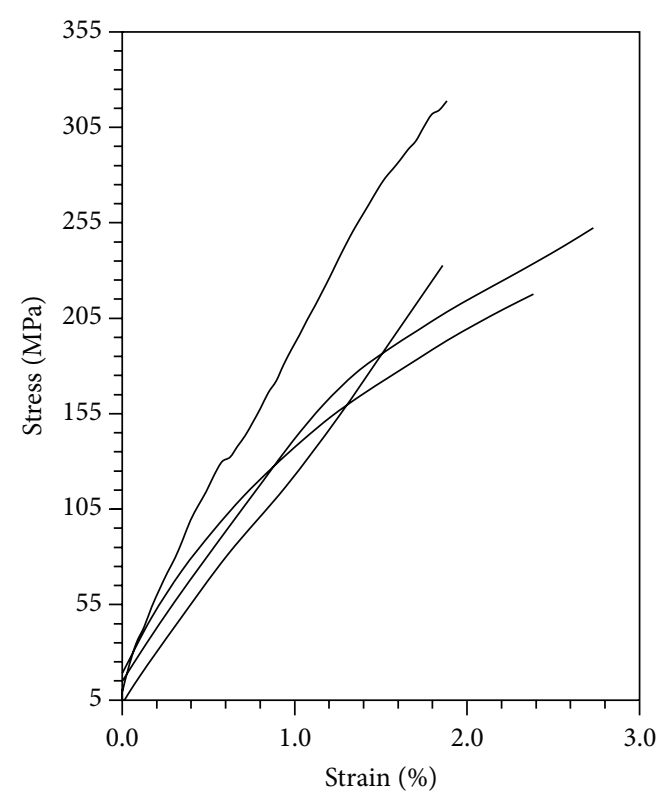

(a)

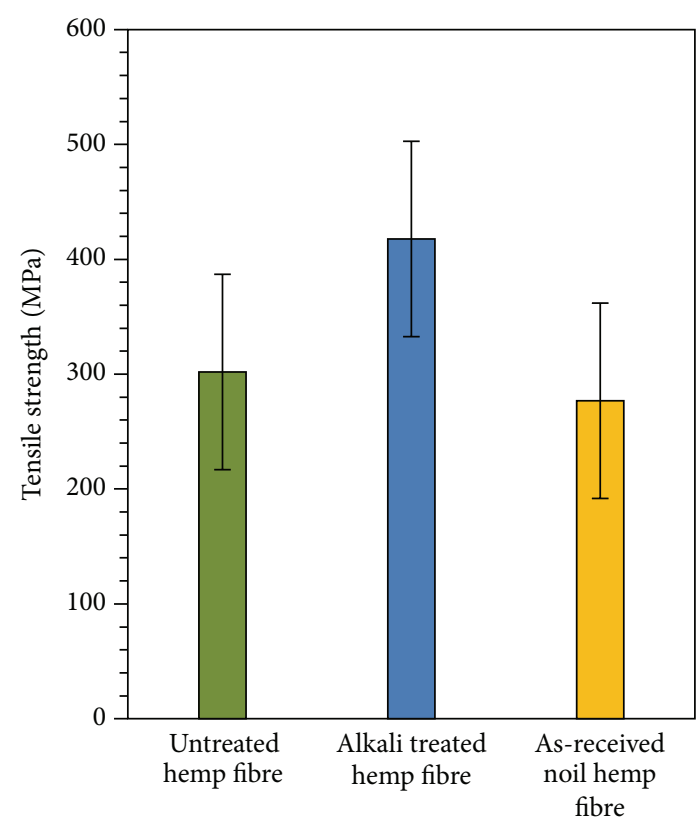

(b)

Figure 8: (a) Typical stress-strain curves of single noil hemp fibre at gauge length of $12 \mathrm{~mm}$ and (b) tensile strength of the untreated, alkali treated, and noil hemp fibres at the same gauge length.

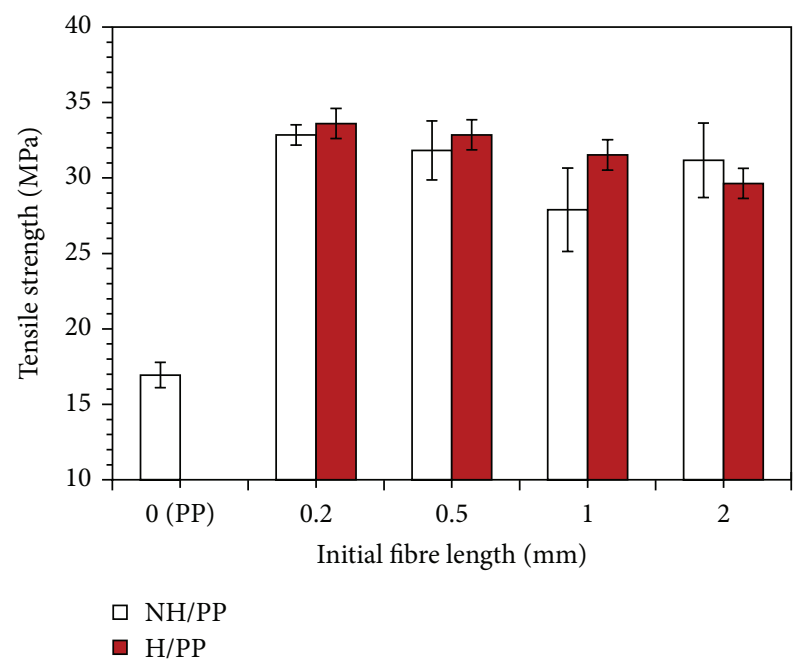

FIgURE 9: The influence of the initial fibre length on tensile strength of the noil (white) and treated hemp (red) fibre reinforced polypropylene composites.

The average flexural strength and flexural modulus of the noil hemp fibre polypropylene (NH/PP) and hemp fibre polypropylene (H/PP) composites as a function of initial fibre length are shown and presented in Table 3 and Figures 12 and 13. As can be seen in Figure 12, the flexural strength increased with addition of $40 \mathrm{wt} \%$ short fibres into the pure polypropylene. The average flexural strength increased with addition of $0.2 \mathrm{~mm}$ short fibres from 12.4 for pure polypropylene to 55.65 for NH/PP and 51.19 for H/PP. Likewise, the flexural modulus

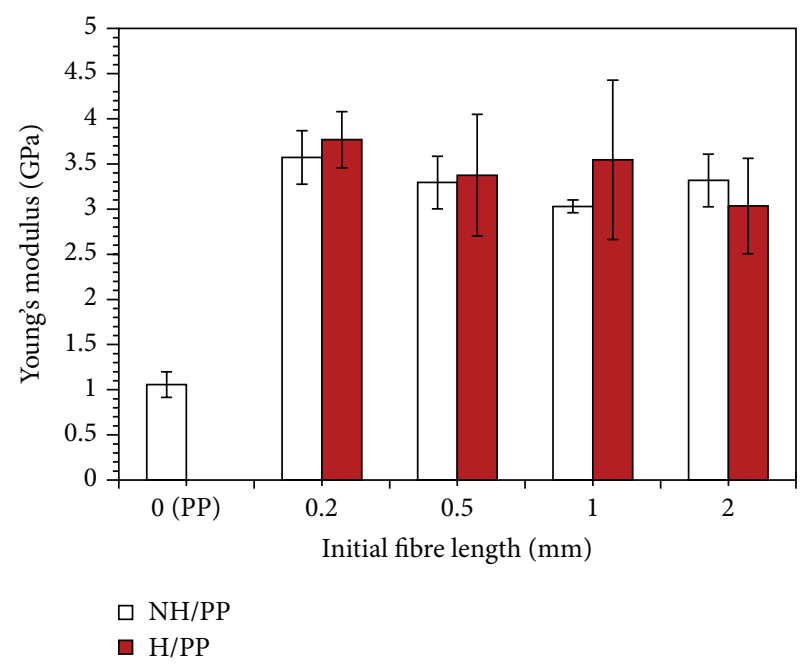

FIgURE 10: The influence of the initial fibre length on Young's modulus of the noil (white) and treated hemp (red) fibre reinforced polypropylene composites.

of the composites raised from approximately $0.5 \mathrm{GPa}$ for polypropylene to higher than $3 \mathrm{GPa}$ for the composites with fibre length of $0.2 \mathrm{~mm}$ (Figure 13). Similar to tensile strength and Young's modulus findings, the flexural strength and flexural modulus of both composites were declined as fibres longer than $0.2 \mathrm{~mm}$ were used to fabricate the composites.

3.6. Impact Strength. It has been concluded so far that reinforcing fibres with initial length of $0.2 \mathrm{~mm}$ can provide 
TABLE 3: Flexural properties of composites with different fibre lengths.

\begin{tabular}{lcccc}
\hline \multirow{2}{*}{ Fibre length $(\mathrm{mm})$} & \multicolumn{2}{c}{ Noil hemp fibre composite } & \multicolumn{2}{c}{ Hemp fibre composite } \\
& Flexural strength $(\mathrm{MPa})$ & Flexural modulus $(\mathrm{GPa})$ & Flexural strength (MPa) & Flexural modulus (GPa) \\
\hline 0.20 & $55.65 \pm 0.98$ & $3.31 \pm 0.14$ & $51.19 \pm 4.21$ & $3.11 \pm 0.22$ \\
0.50 & $53.25 \pm 4.11$ & $3.04 \pm 0.07$ & $51.18 \pm 5.01$ & $3.06 \pm 0.13$ \\
1.00 & $44.05 \pm 4.00$ & $2.76 \pm 0.37$ & $39.63 \pm 0.95$ & $1.95 \pm 0.16$ \\
2.00 & $39.91 \pm 6.77$ & $2.14 \pm 0.43$ & $40.26 \pm 4.01$ & $2.32 \pm 0.27$ \\
\hline
\end{tabular}

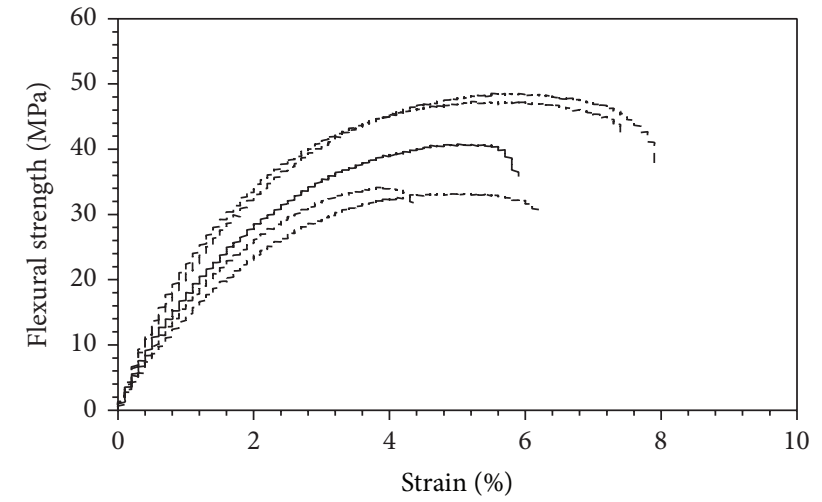

Figure 11: Flexural stress-strain curves for $40 \mathrm{wt} \%$ noil hemp fibre composite with initial fibre length of $2 \mathrm{~mm}$.

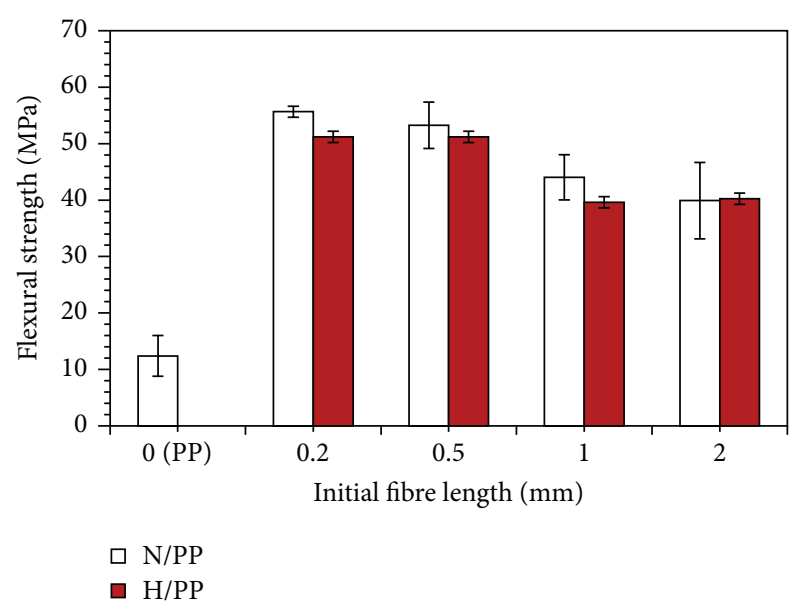

FIGURE 12: The influence of the initial fibre length on flexural strength of the noil (white) and treated hemp (red) fibre reinforced polypropylene composites.

the optimum tensile and flexural properties among all composites. To extend the results, the effect of fibre lengths on impact toughness of the composite samples has been also investigated using impact tests. The impact toughness of a composite is the amount of energy it can absorb through plastic deformation before fracture. Therefore, study on impact properties of the composites can be of great importance when the reinforcing fibres are very short, as short fibres create stress concentration sites in the matrix, which might reduce impact toughness of the materials.

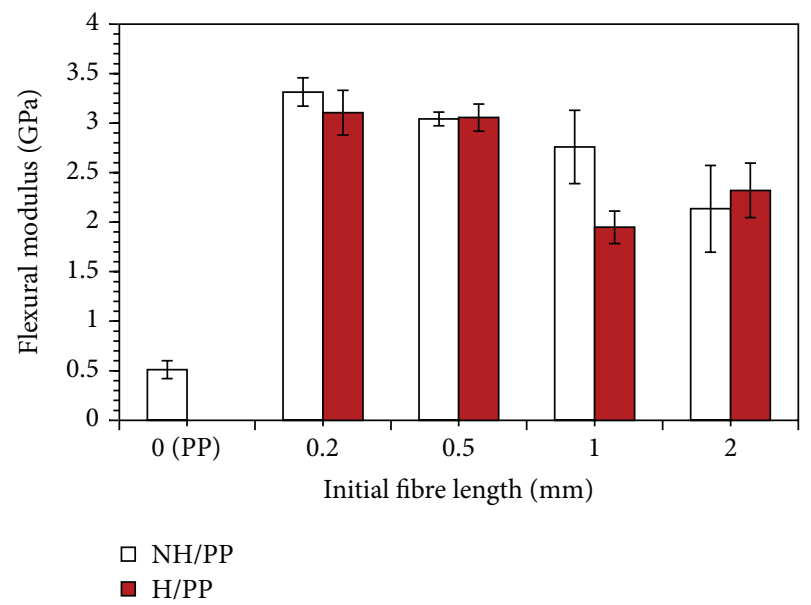

Figure 13: The influence of the initial fibre length on flexural modulus of the noil (white) and treated hemp (red) fibre reinforced polypropylene composites.

Typical impact force-time and impact energy-time curves are shown in Figure 14. The Energy-time curve, shown in Figure 14, was plotted using the calculation of the total area under the force-time curve. Then, the amount of total energy requires to damage the composite can be extracted using the energy-time curve. Belingardi et al. [17] introduced the damage degree (DD) to account for damage accumulation. It was defined as the ratio between the absorbed energy $E_{a}$ and the impact energy $E_{i}\left(E_{a} / E_{i}\right)$.

Once the impact energy $\left(E_{i}\right)$ is high enough, the composite failure eventually can happen. In a case, the specimen does not completely fail; the projectile bounces back from the specimen. The energy created when the projectile bounces back is known as rebounded energy $\left(E_{r}\right)$. When the specimen completely fails, the projectile is not rebound and the rebound energy $\left(E_{r}\right)$ is zero. In this case, complete failure of the specimen happens and DD value becomes 1. The impact force $\left(F_{m}\right)$, maximum impact energy $\left(E_{m}\right)$, absorbed energy $\left(E_{a}\right)$, and rebounded energy $\left(E_{r}\right)$ of the specimens were extracted from corresponding impact forcetime and impact energy-time curves of the composites and then summarised in Tables 4 and 5. Moreover, the changes in peak load, rebounded energy, and damage degree as function of initial fibre length are presented in Figures 15 and 16.

A comparison between the pure PP sample and the composites shows that the $E_{r}$ and DD of the pure PP is higher and lower, respectively. In other words, addition of 
TABLE 4: Impact properties of polypropylene sample.

\begin{tabular}{cccccc}
\hline & $F_{m}(\mathrm{~N})$ & $E_{m}(\mathrm{~J})$ & $E_{a}(\mathrm{~J})$ & $E_{r}(\mathrm{~J})$ & $\mathrm{DD}$ \\
\hline PP sample & $118.50 \pm 0.75$ & $3.05 \pm 0.43$ & $2.41 \pm 0.52$ & $0.64 \pm 0.12$ & $0.79 \pm 0.08$ \\
\hline
\end{tabular}

TABLE 5: Impact properties of composites with different fibre lengths.

\begin{tabular}{|c|c|c|c|c|c|c|c|c|c|c|}
\hline \multirow{2}{*}{$\begin{array}{l}\text { Fibre length } \\
(\mathrm{mm})\end{array}$} & \multicolumn{5}{|c|}{ Noil hemp fibre composite } & \multicolumn{5}{|c|}{ Hemp fibre composite } \\
\hline & $F_{m}(\mathrm{~N})$ & $E_{m}(\mathrm{~J})$ & $E_{a}(\mathrm{~J})$ & $E_{r}(\mathrm{~J})$ & $\mathrm{DD}$ & $F_{m}(\mathrm{~N})$ & $E_{m}(\mathrm{~J})$ & $E_{a}(\mathrm{~J})$ & $E_{r}(\mathrm{~J})$ & DD \\
\hline 0.2 & $191.70 \pm 8.6$ & $2.99 \pm 0.22$ & $2.57 \pm 0.21$ & $0.42 \pm 0.02$ & $0.86 \pm 0.01$ & $175.50 \pm 2.20$ & $2.71 \pm 0.01$ & $2.25 \pm 0.04$ & $0.46 \pm 0.04$ & $0.83 \pm 0.01$ \\
\hline 0.5 & $177.24 \pm 3.16$ & $2.80 \pm 0.17$ & $2.43 \pm 0.12$ & $0.37 \pm 0.01$ & $0.87 \pm 0.01$ & $173.30 \pm 3.12$ & $2.64 \pm 0.08$ & $2.24 \pm 0.07$ & $0.40 \pm 0.01$ & $0.85 \pm 0.01$ \\
\hline 1 & $164.40 \pm 2.31$ & $2.64 \pm 0.25$ & $2.32 \pm 0.26$ & $0.32 \pm 0.08$ & $0.88 \pm 0.02$ & $173.67 \pm 3.83$ & $2.75 \pm 0.13$ & $2.37 \pm 0.12$ & $0.38 \pm 0.01$ & $0.86 \pm 0.00$ \\
\hline 2 & $150.00 \pm 5.65$ & $2.45 \pm 0.63$ & $2.30 \pm 0.51$ & $0.15 \pm 0.06$ & $0.94 \pm 0.01$ & $159.65 \pm 4.55$ & $2.38 \pm 0.06$ & $2.11 \pm 0.18$ & $0.34 \pm 0.06$ & $0.86 \pm 0.02$ \\
\hline
\end{tabular}

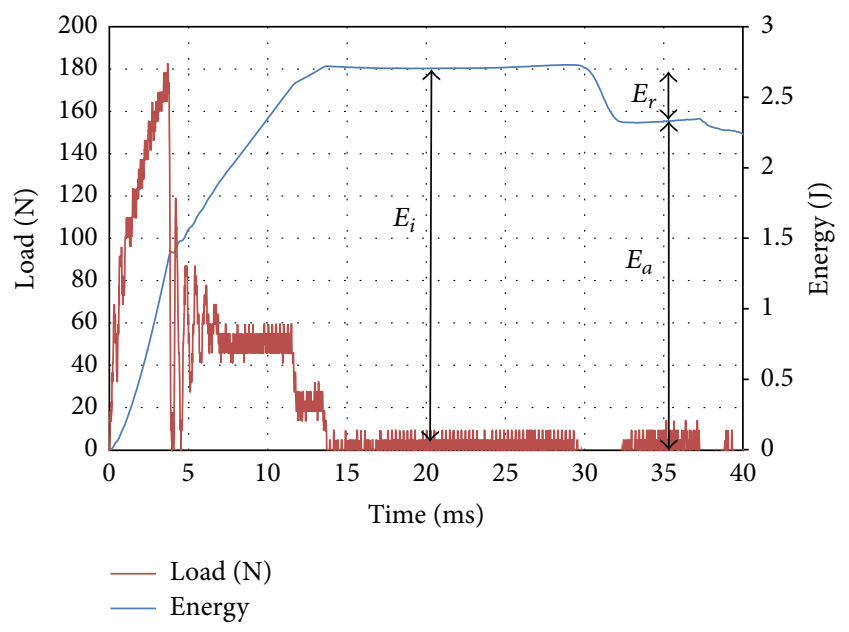

FIgURE 14: Load and energy history curves of a Noil hemp fibre polypropylene composite specimen reinforced with $0.2 \mathrm{~mm}$ Noil fibres.

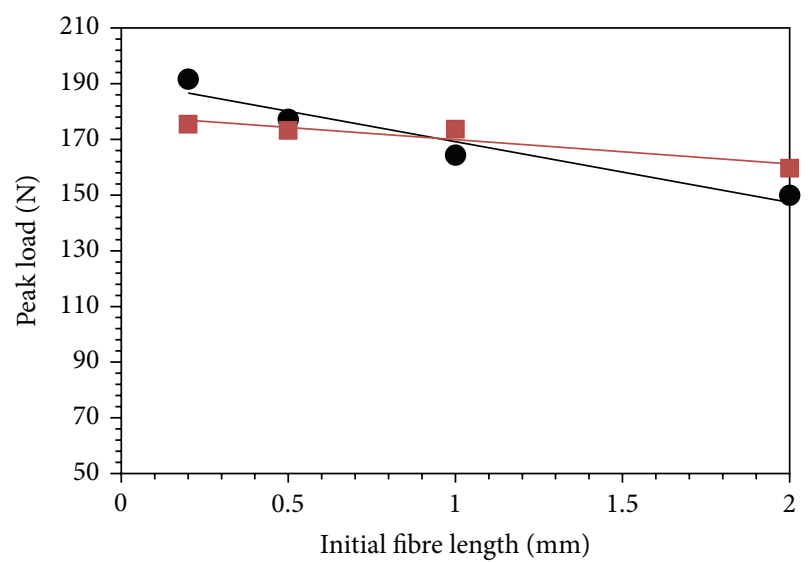

- $\mathrm{NH} / \mathrm{PP}$

FIGURE 15: Effect of initial fibre length on peak load of noil hemp fibre and treated hemp fibre composites. fibres/fillers in the pure reduces the impact properties as expected.

From Figure 15, it can be observed that as fibre length increased the peak load of the composites reduced. Peak load, also known as impact Load, corresponds to the onset of material damage or complete failure. Therefore, the composite with $0.2 \mathrm{~mm}$ initial fibre showed better impact resistance among all other samples.

During impact, compressive, shear, and tensile loadings are applied on the composite samples simultaneously. As aforementioned, fibre agglomerations are more likely to form in composites with longer fibres. Then fibres are not properly wet up in agglomeration sites and crack can be initiated from fibre/matrix interface in the agglomeration sites. As a result, poor dispersion of fibres reduces composite impact resistance during compression, shear, and tensile by reduction of interface bonding between the fibre and matrix in agglomeration sites.

Likewise, Figure 16(a) shows the higher $E_{r}$ values for composites with shorter initial fibres. It indicates that better fibre dispersion and subsequently strong interfaces in the composites with shorter fibres prevented the impactor from penetrating the samples and thus more rebounded energy was observed. Also, the lower DD values as shown in Figure 16(b) indicated that the extent of impact damage was less on composites with shorter fibres. Both noil hemp fibre composites and hemp fibre composites provided almost the same values of impact energy at different initial fibre length. However, as Figure 16(b) shows, the damage degree (DD) values of the noil hemp fibres composites are significantly higher than those of normal hemp fibre due to the fibre weakness (defects/cracks) caused by the degumming process. The impact results gained here are in correlation with their tensile and flexural properties as discussed earlier.

To summarize, the impact test results show that increase in initial fibre length of the composites decreases the maximum load and rebounded energy but increases the damage degree (DD) of the composites. In addition, noil hemp fibres composite represents lower impact properties than hemp fibre composites. 


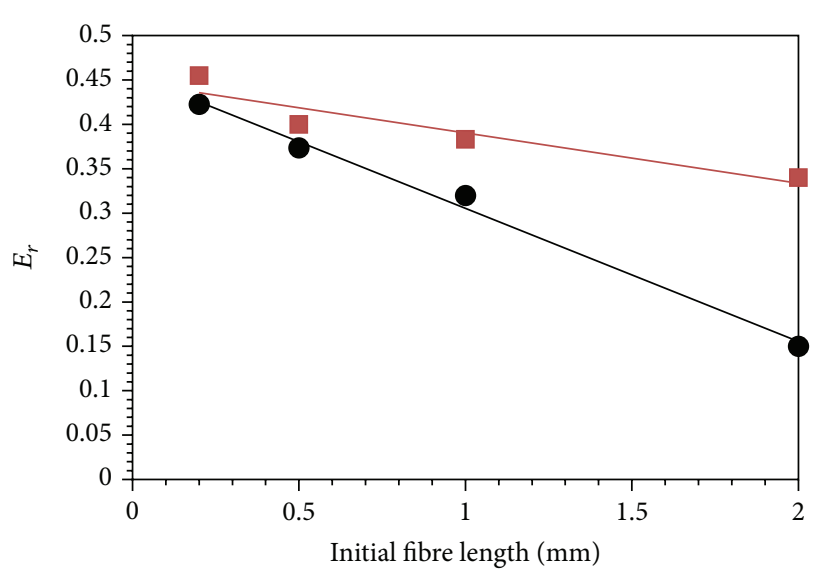

- $\mathrm{NH} / \mathrm{PP}$

- H/PP

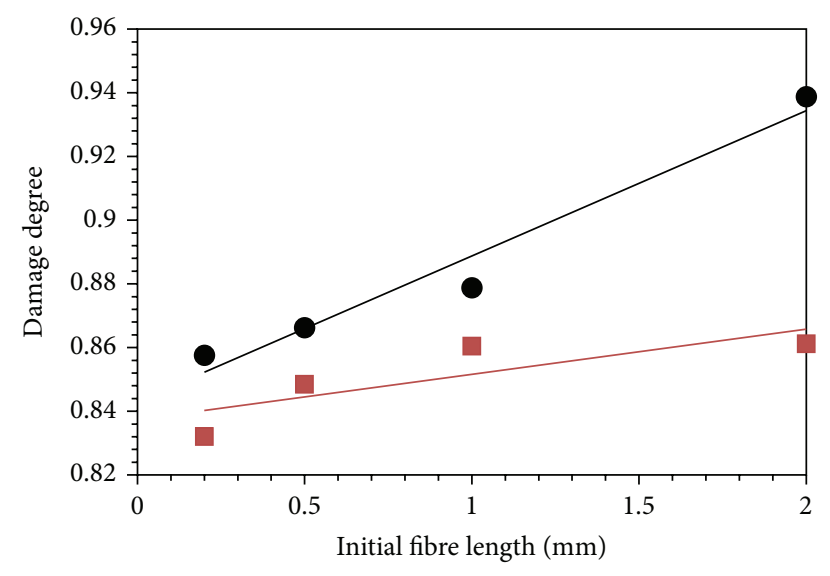

- $\mathrm{NH} / \mathrm{PP}$

- $\mathrm{H} / \mathrm{PP}$

(a)

(b)

FIGURE 16: Effect of initial fibre length on impact properties of noil hemp fibre and treated hemp fibre composites (a) impact energy and (b) damage degree.

\section{Conclusion}

In this paper, noil fibre and normal treated and untreated hemp fibre were characterized. Also, the influence of initial fibre length on mechanical properties of ground fibre polypropylene composites was studied. The following can be concluded.

Alkali treatment of normal hemp fibres could remove cementing materials (pectin, hemicellulose, and lignin) partial/completely from surface of the fibres.

Noil hemp fibre contains almost the same type of chemical components and morphology as $5 \mathrm{wt} \%$ alkali treated hemp fibres contain. Therefore, noil hemp fibres do not require any chemical treatments to remove the lignocellulosic amorphous materials.

The noil hemp fibres delivered lower tensile properties than treated hemp fibres due to the cellulose degradations (fibre defects) because of overdegumming happens in textile processing. The ground fibres are still capable of reinforcing the polypropylene matrices.

Hemp and noil hemp powder (fillers) with original length of $0.2 \mathrm{~mm}$ resulted in highest tensile, flexural, and impact properties of the composites due to better dispersion of the fillers and more homogenous structure of the composites. However, as the initial fibre length increased, the tensile, flexural, and impact strength of the samples decreased slightly.

\section{Conflict of Interests}

The authors declare that there is no conflict of interests regarding the publication of this paper.

\section{References}

[1] H. Ku, H. Wang, N. Pattarachaiyakoop, and M. Trada, "A review on the tensile properties of natural fiber reinforced polymer composites," Composites Part B: Engineering, vol. 42, no. 4, pp. 856-873, 2011.

[2] Z.-Y. Sun, H.-S. Han, and G.-C. Dai, "Mechanical properties of injection-molded natural fiber-reinforced polypropylene composites: formulation and compounding processes," Journal of Reinforced Plastics and Composites, vol. 29, no. 5, pp. 637-650, 2010.

[3] R. Gosselin, D. Rodrigue, and B. Riedl, "Injection molding of postconsumer wood-plastic composites II: mechanical properties," Journal of Thermoplastic Composite Materials, vol. 19, no. 6, pp. 659-669, 2006.

[4] P. Niu, B. Liu, X. Wei, X. Wang, and J. Yang, "Study on mechanical properties and thermal stability of polypropylene/hemp fiber composites," Journal of Reinforced Plastics and Composites, vol. 30, no. 1, pp. 36-44, 2011.

[5] M. Bengtsson, M. L. Baillif, and K. Oksman, "Extrusion and mechanical properties of highly filled cellulose fibrepolypropylene composites," Composites Part A: Applied Science and Manufacturing, vol. 38, no. 8, pp. 1922-1931, 2007.

[6] D. Maldas, B. V. Kokta, and C. Daneault, "Influence of coupling agents and treatments on the mechanical-properties of cellulose fiber-polystyrene composites," Journal of Applied Polymer Science, vol. 37, no. 3, pp. 751-775, 1989.

[7] A. Etaati, S. A. Mehdizadeh, H. Wang, and S. Pather, "Vibration damping characteristics of short hemp fibre thermoplastic composites," Journal of Reinforced Plastics and Composites, vol. 33, no. 4, pp. 330-341, 2014.

[8] Z. L. Yan, H. Wang, K. T. Lau et al., "Reinforcement of polypropylene with hemp fibres," Composites Part B: Engineering, vol. 46, pp. 221-226, 2013.

[9] G. Zhang and M. R. Thompson, "Reduced fibre breakage in a glass-fibre reinforced thermoplastic through foaming," Composites Science and Technology, vol. 65, no. 14, pp. 22402249, 2005.

[10] A. Etaati, H. Wang, S. Pather, Z. Yan, and S. Abdanan Mehdizadeh, "3D X-ray microtomography study on fibre breakage in noil hemp fibre reinforced polypropylene composites," Composites Part B: Engineering, vol. 50, pp. 239-246, 2013. 
[11] A. Etaati, S. Pather, Z. Fang, and H. Wang, "The study of fibre/matrix bond strength in short hemp polypropylene composites from dynamic mechanical analysis," Composites Part B: Engineering, vol. 62, pp. 19-28, 2014.

[12] A. Etaati, S. Pather, F. Cardona, and H. Wang, "Injection molded noil hemp fiber composites: Interfacial shear strength, fiber strength, and aspect ratio," Polymer Composites, 2014.

[13] S. Korte and M. P. Staiger, "Effect of processing route on the composition and properties of hemp fibre," Fibers and Polymers, vol. 9, no. 5, pp. 593-603, 2008.

[14] A. Sonia and K. Priya Dasan, "Chemical, morphology and thermal evaluation of cellulose microfibers obtained from Hibiscus sabdariffa," Carbohydrate Polymers, vol. 92, no. 1, pp. 668-674, 2013.

[15] C. Baley, "Influence of kink bands on the tensile strength of flax fibers," Journal of Materials Science, vol. 39, no. 1, pp. 331-334, 2004.

[16] M. Symington, W. M. Banks, J. L. Thomason, R. A. Pethrick, and O. David-West, "Kink bands in flax and hemp polyester composites," in Proceedings of the 18th International Conference on Composites Materials (ICCM '11), Jeju Island, Republic of Korea, August 2011.

[17] G. Belingardi, F. Grasso, and R. Vadori, "Energy absorption and damage degree in impact testing of composite materials," in Experimental Mechanics, Vols 1 and 2: Advances in Design, Testing and Analysis, I. M. Allison, Ed., pp. 279-285, 1998.

[18] D. Dai and M. Fan, "Characteristic and performance of elementary hemp fibre," Materials Sciences and Applications, vol. 1, no. 6, pp. 336-342, 2010.

[19] H. L. Liu, L. L. You, H. B. Jin, and W. D. Yu, "Influence of alkali treatment on the structure and properties of hemp fibers," Fibers and Polymers, vol. 14, no. 3, pp. 389-395, 2013.

[20] D. Sedan, C. Pagnoux, T. Chotard et al., "Effect of calcium rich and alkaline solutions on the chemical behaviour of hemp fibres," Journal of Materials Science, vol. 42, no. 22, pp. 93369342, 2007.

[21] M. Le Troëdec, C. S. Peyratout, A. Smith, and T. Chotard, "Influence of various chemical treatments on the interactions between hemp fibres and a lime matrix," Journal of the European Ceramic Society, vol. 29, no. 10, pp. 1861-1868, 2009. 

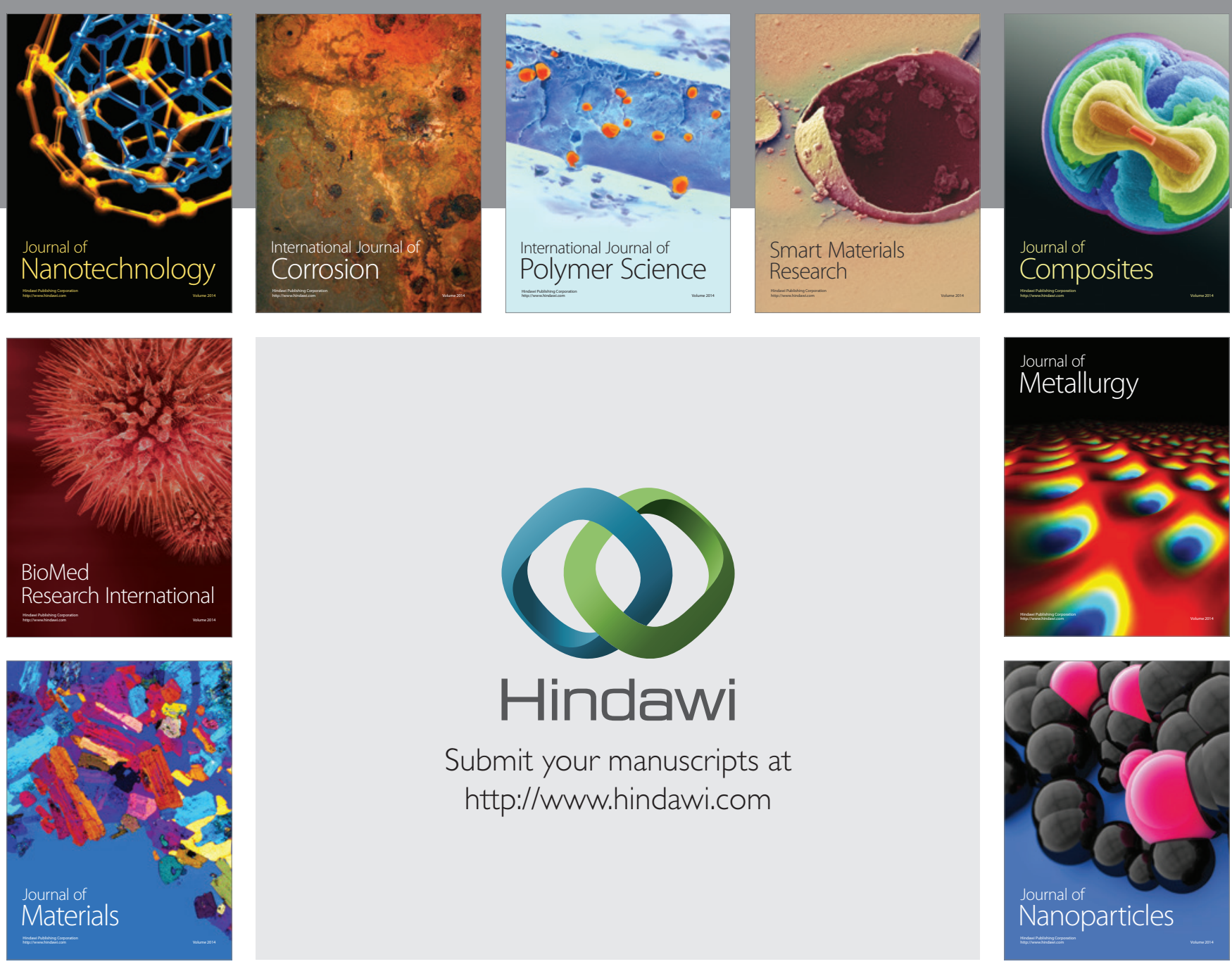

Submit your manuscripts at http://www.hindawi.com
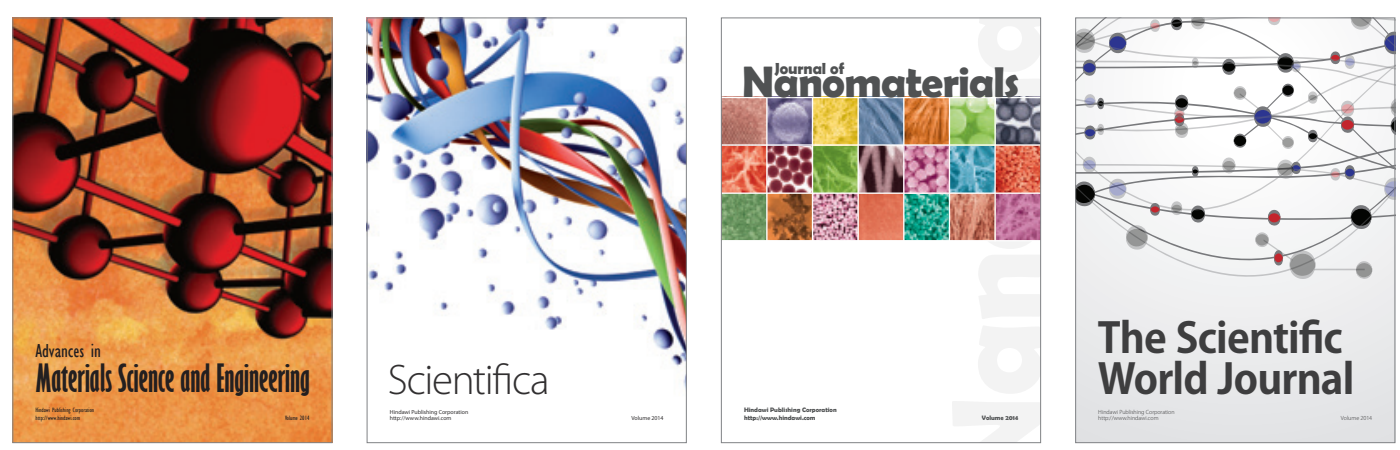

\section{The Scientific World Journal}
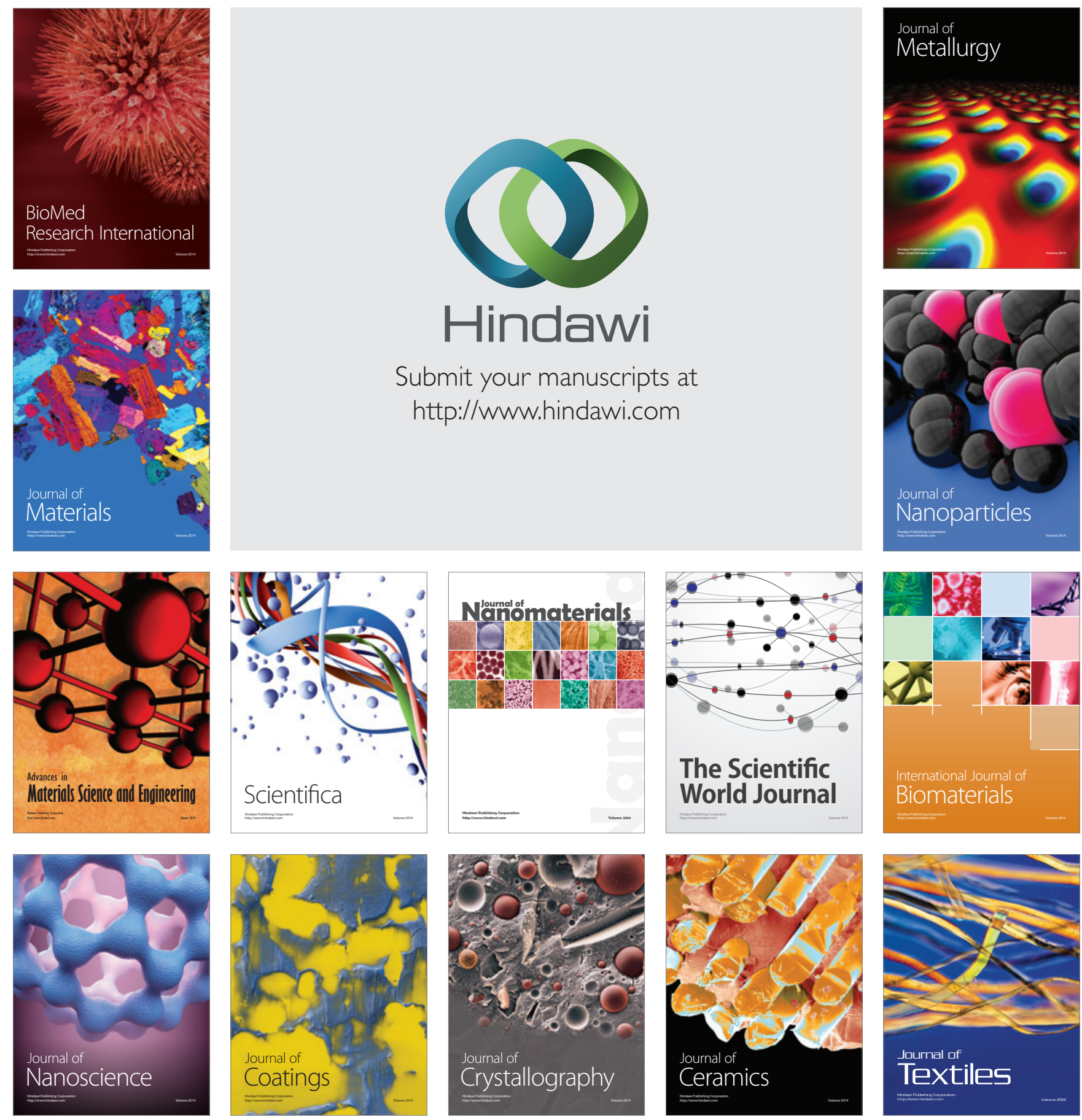